\title{
EVALUATE THE CYLINDRICAL RUBBER FENDER RESPONSE UNDER DYNAMIC LOAD
}

\author{
ANIS MOHAMAD ALI ${ }^{1}$, MOHAMAD J. K. ESSA ${ }^{1}$ and ABDULAMEER QASIM HASSAN ${ }^{2}$ \\ ${ }^{I}$ Civil Engineering Dept., Basrah University / Basrah, Iraq \\ ${ }^{2}$ Environment and Pollution Engineering Dept., South Technical University, Basrah, Iraq
}

\begin{abstract}
Fender systems are very important part in marine and offshore structures. They are used to decrease the influence of impact forces of vessels during berthing or mooring conditions. This paper focuses on evaluating the response of a cylindrical rubber fender (Length $=5 \mathrm{~m}$, outer diameter $=0.5 \mathrm{~m}$ and inner diameter $=0.25 \mathrm{~m}$ ) subjected to impact load that comes from a mooring ship with capacity 330,000 DWT. Three curves are drawn representing the mechanical response of the cylindrical rubber fender under the influence of impact load, the first curve is the highest response and represents the result of the impact due to the initial speed of ship, but the other curves represent the reaction of cylindrical rubber fender after the initial impact.
\end{abstract}

Keywords: Cylindrical Rubber fender, Dynamic analysis, Fender reactiontime.

\section{Introduction}

In order to obtain a good result when designing a marine fender system, the dynamic interaction between the fender and ships is very essential. The dynamic analysis is capable to explain the absorbed energy by fenders accurately and describe the requirements of an operational performance. Many analyses methods are available, which describe the energy of a mooring ship that to be reduced and evaluating the reaction force for the fender. The energy method is the first, commonly and simple approach that used. Lee [1] using the energy method to estimating the hydrodynamic factors and stiffness's of overall system, the values which is used are empirical and ignored the damping of the system. Alternate statistical methods consider data obtained from model measurements to calculate the design value of energy due to mooring impact and absorption energy of fenders. Sevedsen [2] calculated the design value of the absorbed energy by a fender with selected amount of risk in the design; the disadvantage of this technique is in obtaining the statistical data for the problem. Kim [3] suggested a simpler and approximate method, the idea is dependent on the use of time average of the kinetic energy of the mooring ship during the time interval of fender compression; this method is applicable to ships in calm water and berthing broadside. Van Cortmerssen [4] developed a solution for time domain to forces and motions; these methods use Impulse Response Function Techniques. 


\section{Dynamic Response of the Fender}

The simple model shown in Figure 1 explains the dynamic of a ship impacting a fender. The fender is represented by a frictionless mass (Mf) connected to a dashpot and spring and the ship is represented by a second frictionless mass with first velocity Vo. At first, before impact the fender it is in static

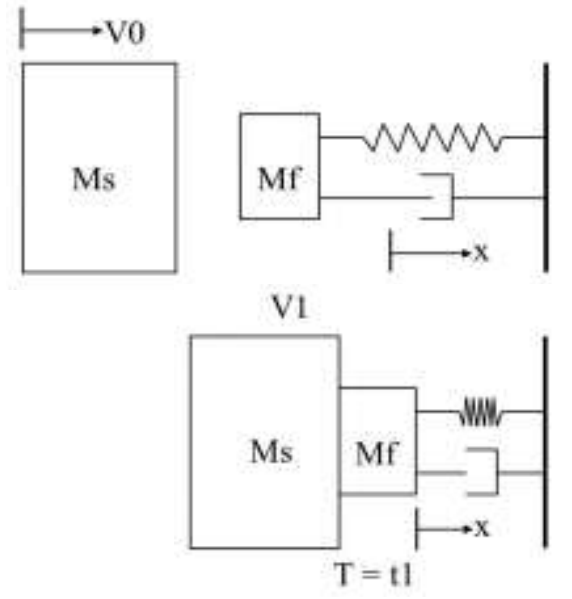

equilibrium. When the impact happened, the ship mass and fender mass becomes coupled then the spring is compacted by the ship mass with slow and stopped at maximum displacement. The strain energy is kept in the spring and pushed the ship return to the stability case where it discrete with the fender.

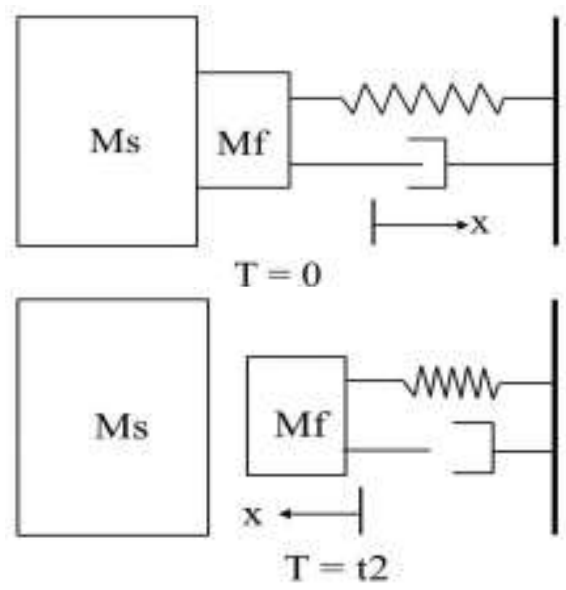

Figure 1; the dynamics of a ship impacting a cylindrical rubber fender

\section{Kinetic Energy of Fender}

The behaviour of a fender system to dynamic forces is based on the stiffness's and damping properties of the fender. The fender stiffness can be obtained from the test performed by assuming the fender is a perfectly elastic, while the damping properties of fender are not estimated. The design of fender system is mostly dependent on the energy considerations. The kinetic energy of a ship is absorbed by the fender and transformed to the structure with equal value of energy. The general formulation of kinetic energy can be calculated using Equation 1 .

$E=\frac{1}{2} M_{S} V_{0}^{2} C_{M} C_{E} C_{S}$
Where $M_{S}$ ship mass, $V_{0}$ initial velocity of ships, $C_{M}$ add mass coefficient, $C_{E}$ eccentricity coefficient, and $C_{S}$ structural deformation coefficient.

The absorbed energy of the fender is represented by the work performed by the fender, this kinetic energy is expressed in equation 2, and this equation is not dependent of the fender shape and the fender properties (Load - deflection curve) [5].

$E=W=\int_{y_{t_{0}}}^{y_{t_{1}}} F(t) \cdot d y$

\section{Dynamic Model}

The calculation of free motion is governed by the second low of Newton's; it's known by the partial differential 
formulation [6] for a system with single degree of freedom,

$$
m \ddot{y}+c \dot{y}+k y=0
$$

Where $k, c$ and $m$ represent the stiffness, damping and mass, and, $y, \dot{y}$, and $\ddot{y}$, are the displacement, velocity, and acceleration. For multi-degree of freedom structure, there is a system of $\mathrm{N}$ number of natural frequencies and $\mathrm{N}$ combined differential equation containing $\mathrm{N}$ number of modes. A multi-degree of freedom structure can be expressed in terms of its modals coordinate; the formulation of dynamic motion is alike procedure to the single degree of freedom procedure.

$M_{n} \ddot{q}_{n}+C_{n} \dot{q}_{n}+K_{n} q_{n}=0$

Where,

$M_{n}=\bar{\emptyset}_{n}^{T} m \bar{\emptyset}_{n} \quad, \quad C_{n}=\bar{\emptyset}_{n}^{T} c \bar{\emptyset}_{n} \quad$ and $K_{n}=\bar{\emptyset}_{n}^{T} k \bar{\emptyset}_{n}$

The amount of modal $\ddot{q}_{n}, \dot{q}_{n}$ and $q_{n}$, in Eq. (4) is similar to $\ddot{y}, \dot{y}$, and $y$, in the one dimension equation of dynamic motion. Where $\bar{\emptyset}_{n}$ represents the vector that defines the deflected shape of the lump mass for any model of oscillation. Eq. (4) become:

$\ddot{q}_{n}+2 \xi_{n} \omega_{n} \dot{q}_{n}+\omega_{n}{ }^{2} q_{n}=0$

The result of equation (6) is analogous form to the result of a single degree of freedom system calculated by using

$$
\begin{aligned}
& q_{n}(t)=\left(q_{n}(0) \cos \omega_{n d} t+\right. \\
& \left.\left(\frac{\dot{q}_{n}(0)+\xi_{n} \omega_{n} q_{n}(0)}{\omega_{n d}}\right) \sin \omega_{n d} t\right) \exp \left(-\xi_{n} \omega_{n} t\right)
\end{aligned}
$$

Where,

$$
\begin{aligned}
& q_{n}(0)=\frac{\bar{\emptyset}_{n}^{T} m \bar{y}(0)}{M_{n}} \\
& \text { and } \quad \dot{q}_{n}(0)=\frac{\bar{\emptyset}_{n}^{T} m \bar{y}(0)}{M_{n}}
\end{aligned}
$$

The values of $q_{n}(0)$ and $\dot{q}_{n}(0)$ represent the primary conditions of the structure. Equation (7) is simplified to the following;

$q_{n}(t)=$

$\left(\left(\frac{\dot{q}_{n}(0)}{\omega_{n d}}\right) \sin \omega_{n d} t\right) \exp \left(-\xi_{n} \omega_{n} t\right)$

The natural frequency of damped of all modes of oscillation $\left(\omega_{n d}\right)$ is a function of the damping ratio $\left(\xi_{n}\right)$ and the natural frequency of undamped $\left(\omega_{n}\right)$ given by

$$
\omega_{n d}=\omega_{n} \sqrt{1-\xi_{n}^{2}}
$$

The natural frequency of undamped of all modes $\left(\omega_{n}\right)$ is calculated by solving the typical equation

$$
\operatorname{det}\left[k-\omega_{n} m\right]=0
$$

And the identical_mode shape $\left(\bar{\emptyset}_{n}\right)$ is calculated by using equation (12)

$$
\left[k-\omega_{n} m\right] \bar{\varnothing}_{n}=0
$$

Also the value of $\bar{\emptyset}_{n}$ and $\omega_{n}$ is calculated together by using the Eigen value function in the MATLAB program. Multiplying Eq. (9) by the identical mode shapes and summarization the behaviour of any mode to calculated the timedisplacement varying.

$$
\begin{aligned}
& \bar{y}(t)= \\
& \sum_{n=1}^{\infty} \bar{\emptyset}_{n}\left(\left(\frac{\dot{y}(0)}{\omega_{n d}}\right) \sin \omega_{n d} t\right) \exp \left(-\xi_{n} \omega_{n} t\right)
\end{aligned}
$$


Similarly, the applied force to the structure during the cylindrical rubber fender $(F)$ is calculated from the spring stiffness and displacement at the upper most nodes

$F(t)=k_{f} \cdot y(t)$

\section{Application}

Cylindrical Rubber fender is used in this study and the analytical method is used to

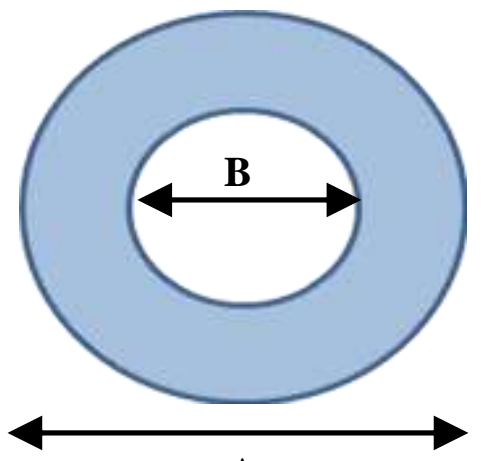

A explain the reaction force for the fender. The capacity of a tanker ship is 330000 DWT and the dimensions is length 415 $\mathrm{m}$, beam $63 \mathrm{~m}$, draft $35 \mathrm{~m}$ and the approaching velocity $\mathrm{V} 0=15 \mathrm{~cm} / \mathrm{sec}$. the cylindrical rubber fender with length 5 $\mathrm{m}$, outer diameter $0.5 \mathrm{~m}$ and inside diameter $0.25 \mathrm{~m}$, the characteristics of fender as shown in the figures 2 and 3. An average damping of $19 \%$ was estimated using the velocity time history of the ship.

Figure2:- Cylindrical Rubber Fender dimensions and properties [7]
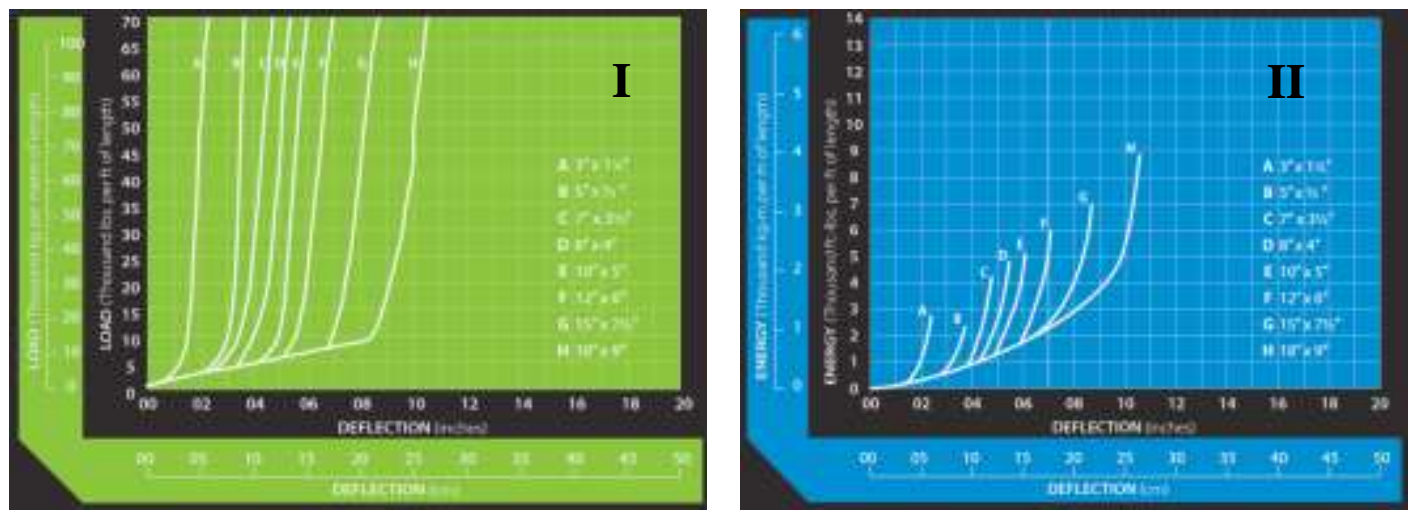

Figure3:- cylindrical rubber fender properties I- Load Deflection Curves, II- Energy Deflection Curves [7]

\section{Results}

Figure 3 shows the reaction force as a function of time to the cylindrical rubber fender, three curve are drawn, the first curve represents the first case of impact the velocity at maximum value $(V 0=15$ $\mathrm{m} / \mathrm{sec}$ ) after that the ship is pushed back by the fender reaction and return to impact fender with velocity $V 1$ and the reaction of fender is less than the first case because of the reduction in the 
energy applied, then the reaction force is decrease with time and applied energy. In design offshore structure the envelope of the reaction force is taken to find the response of these structures.

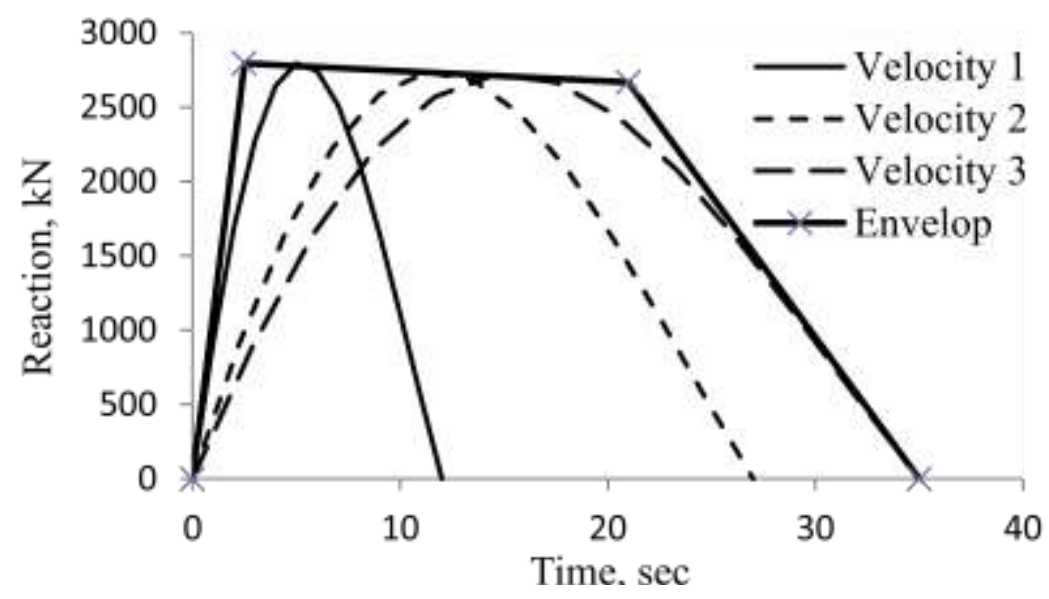

Figure 4:- Reaction-Time Relation for Cylindrical Rubber fender

\section{7- Conclusions}

The new developed method was used to calculate the reaction force as a function of time for cylindrical rubber fender and a tanker ship with capacity 330000 DWT only. This method is different from the classical kinetic energy method; the dynamic method assumes the energy losses in the system that happens through ship impact. This method is in good agreement compared with the method used by Al-Jasim [8].

\section{References}

[1] Lee,T.T., “A Design Criteria Recommended for Marine Fender Systems", Proceedings of the 11th International Conference on Coastal Engineering, London, ASCE, 1968.

[2]Svendsen, I. A., "The Statistical Approach", PIANC International Study Commission for Improving Fender Design Systems, Edinburgh, 1981.
[3] Kim, C. H.,"Sway Added Mass and Impact Load of a Large Tank to a Jetty in Shallow Water", The Arctic-Offshore Deep sea Systems Symposium, ASME, 1982.

[4] Van Cortmerssen, G.,"The Motions of a Moored Ship in Waves", Thesis, The Delft University of Technology, The Netherlands, 1976.

[5] Blok, J.J., Brozius, L.H., and Dekker, J.N." "The Impact Loads of Ships Colliding With Fixed Structures" Offshore Technology Conference, Texas, May 2-5, 1983

[6] Christopher D. P. Baxter, "Field Study of Composite Piles in the Marine Environment" University of Rhode Island, July 2005

[7] Goodyear Engineered Products, Marine Fenders, Canada

[8] Al-Jasim, "Dynamic Analysis of Offshore Template Structures with SoilStructure Interaction", Ph. D., Eng. thesis, Engineering College University of Basrah, 2000. 